\title{
Education and Income Inequality: the Role of a Social Protection System
}

\author{
Alexandra Rillaers*
}

May 25, 1999

\begin{abstract}
In this paper we aim to understand how unemployment benefits may affect investment in education when the latter is characterized by uncertain returns. This is done in an overlapping generations model in which endogenous growth is introduced through human capital accumulation. We develop a numerical example of the model in order to reproduce some key differences between the European versus the North American economy; differences that, according to this model, result from the different degree of social protection characterizing both economies.
\end{abstract}

Keywords: uncertainty, education, income inequality.

JEL classification: D81, H55, I29.

\footnotetext{
*Address: IRES, Université catholique de Louvain. 3, Place Montesquieu. B-1348 Louvain-la-Neuve. Belgium. e-mail: rillaers@ires.ucl.ac.be.

${ }^{1}$ Helpful comments are gratefully acknowledged to Fabrice Collard, David de la Croix and Jorge Durán. I am also very grateful to Henri Sneessens for very clarifying suggestions. Usual disclaimers apply. The financial support from the Fonds de Développement Scientifique is gratefully acknowledged. This research is also part of a research program supported by the Belgian Program on Interuniversity Poles of Attraction (PAI n ${ }^{\circ}$ P $/ 01$ ).
} 


\section{Introduction}

There has been an extensive debate on to what extent large systems of social protection do or do not affect economic development (See Jonas Agell and Ohlsson 1997 for a survey). The European and the North American welfare states typically constitute two different representative models of social protection systems adopted in developed countries. The former being characterized by large social spending contrasts with the latter, much more reduced and incentive-based. The comparative analysis between these two models has therefore been an important tool in the context of this academic debate. On one hand, distortion of incentives caused by and rigidities resulting from these systems have been pointed out as a source of economic growth slowdowns (See Lindbeck et. al. 1993, Lindbeck et. al. 1994 and Drèze and Malinvaud 1994) and as efficiency decreasing (See Dellas 1997). Health, educational spending, social protection measures which reduces income inequality on the other hand, may be considered productivity and hence growth enhancing (Atkinson 1995 and Persson and Tabellini 1994).

Part of this debate has focused on the role and the financing of education. Education is a long run investment project whose risky nature is widely accepted and incorporated in the literature on human capital (See Levhari and Weiss 1974, Williams 1979, Snow and Warren 1990). The risk factor results from the uncertainty characterizing the returns to educational investment, and hence future labor earnings. This uncertainty is often likely to induce lower levels of educational investment (See Levhari and Weiss 1974, Williams 1979, Snow and Warren 1990). The relevance of this phenomenon becomes obvious as soon as one accepts the role of human capital and hence of education in economic development.

In this paper we consider a model in which human capital accumulation through educational investment generates endogenous growth. Education is assumed to be individually financed in an incomplete credit market: in order to produce human capital in his first life's period, an agent contracts a debt which he will have to repay in his second life's period. Returns to educational investment are characterized by uncertainty, leading to investment levels which are lower than in the absence of such uncertainty (see Rillaers and Durán 1998). We study whether the introduction of unemployment benefits may encourage investment in education and hence stimulate long run growth, as they would reduce the uncertainty of future income. We assume that the government introduces an unemployment benefits scheme financed by taxes, by which agents will be ensured a minimum income: some percentage of average labor income, -the replacement ratio-, will be considered as a 
poverty threshold which will also constitute the unemployment benefit the government wants to guarantee. Agents whose labor earnings are below this threshold, will choose not to work and to join the public protection program receiving the unemployment benefit. Those whose labor earnings are above this threshold will choose to supply their effective labor. The introduction of these unemployment benefits will therefore cause unemployment.

The discussion will be carried out in an overlapping generations model building on previous work by Michel (1993) and Rillaers and Durán (1998). It is shown that the introduction of an unemployment benefit has two opposite effects on individual educational investment; on the one hand it is likely to reduce incentives to invest in education, as it guarantees a minimum income independent of individual effort and productivity; on the other hand, if relaxing the borrowing limit, an unemployment benefit may allow for higher levels of indebtedness and thus of educational investment, which will be taken advantage of whenever the borrowing constraint is severe. Whether the aggregate effect on educational investment will be positive or negative depends on which of the two effects dominates. Hence, the results obtained do not unambiguously point in favor of unemployment benefits, at least if economic growth is our only concern.

The presence of unemployment benefits has however other consequences like reducing income inequality, which may be indirectly growth enhancing. According to Persson and Tabellini (1994) income inequality reduces economic growth, as it promotes distributive struggles, discouraging growthpromoting activities. Alesina and Rodrik (1991) too argue that a less equal distribution of wealth leads to a lower rate of economic growth, due to the resulting majority voting on tax rates. Our model is not defined to study these effects of income inequality on growth; however, in the second part of this paper we will examine the implications of reduced wage inequality in terms of welfare. To do so we develop a numerical example of the model, which also aims to reproduce European and North American statistics. In general, we investigate whether the introduction of an unemployment insurance system helps the model to better reproduce European data while the case without such a social protection system reflects more the North American economy. More particularly, we analyze whether the presence of unemployment benefits provides a possible explanation for the differences between the European and the North American economy in terms of unemployment rate, labor productivity, education level and income inequality.

The paper is organized as follows: the first section describes the model, and analyzes and discusses the behavior of this economy. In section 2 we develop a numerical example of the model such as to reproduce some stylized 
facts which characterize the economies of Europe and of the United States. Section 3 contains the concluding remarks.

\section{The model}

We essentially build on previous work by Michel (1993) and more particularly on a model by Rillaers and Durán (1998); an overlapping generations model in which human capital accumulation accounts for endogenous growth, and in which the returns to education are uncertain. We extend this model introducing unemployment benefits in order to analyze their impact on educational spending, and hence on long run growth.

\subsection{The household's behavior}

In each period $t$ a new generation consisting of $N_{t}$ individuals is born. The number of individuals of each generation grows at a constant rate $n$; so we have that $N_{t}=(1+n) N_{t-1}$. Consequently the total population also grows at the rate $n$. The model is a three-period overlapping generations model. In the first period the agents do not work, neither consume, but decide how much to spend on their education $e_{t}$. This amount is borrowed on the capital market. The individual human capital accumulation rule is given by

$$
h_{t}=z_{t} H_{t-1}^{1-\beta} e_{t}^{\beta}
$$

where $H_{t-1}$ is the existing average stock of human capital. $z_{t}$ represents an individually specified ability shock. It is assumed that each individual is endowed with a different ability to take advantage of his educational investment in terms of human capital formation. This ability is assumed to be not observable ex ante, and to be only revealed once the agent has decided upon his educational investment. As a consequence a same level of education will not necessarily provide each individual with a same level of human capital ${ }^{2}$. The distribution of the shock however, is assumed to be known to the agents; in particular we will assume a uniform distribution, $z_{t} \sim U[a, b]$ with $a>0$. The density function is therefore constant, $f\left(z_{t}\right)=(b-a)^{-1}$, and we know that $a=\mu-\sqrt{3} \sigma$, and $b=\mu+\sqrt{3} \sigma$ where $\mu$ and $\sigma$ are the mean and the

\footnotetext{
${ }^{2}$ This ability to accumulate human capital can be partially innate, but it can also be assumed to be affected by external factors, as the quality of schooling and the family background (See Schultz 1961, Becker 1975, Card and Krueger 1992, Kodde 1986, Altonji and Dunn 1996).
} 
standard deviation of the distribution respectively. $\beta \in(0,1)$ measures the relative weight of individual investment in the human capital accumulation function.

The average human capital stock in the economy is given by

$$
H_{t}=\int h_{t}\left(z_{t}\right) f\left(z_{t}\right) d z_{t}=\mu H_{t-1}^{1-\beta} e_{t}^{\beta}
$$

where $\mu$ is the unconditional mean of $z_{t}$. The absence of uncertainty at the aggregate level implies that prices, real wage per efficiency unit $w_{t}$, and interest rate $r_{t}$, are deterministic.

We assume that the government provides an unemployment benefit $\Omega_{t}$. Agents with labor revenues below these benefits will choose to join the social protection program. The others, whose investment in education results in relatively higher returns, will prefer to work, earning a labor income which hence still depends on the ability shock they were hit by. In their second life's period all individuals will repay their debt $\left(1+r_{t}\right) e_{t}$, consume a part $c_{t}$ of their income, -labor earnings or unemployment benefit-, and save the remaining part $s_{t}$ in order to consume $d_{t+1}=\left(1+r_{t}\right) s_{t}$ in their third life-period, when they retire.

Individual preferences are represented by a discounted sum of instantaneous utilities, each of them being CES, with $\theta>0$ the inverse of elasticity of substitution. Future utility is discounted at a constant exogenous rate $\rho \in(0,1)$. The problem consists in two steps and is solved backward. For a given investment $e_{t}$ and ability shock $z_{t}$, the agent chooses $s_{t}$ in order to maximize his utility

$$
U\left(c_{t}, d_{t+1}\right)=\frac{c_{t}^{1-\theta}}{1-\theta}+\frac{1}{1+\rho} \frac{d_{t+1}^{1-\theta}}{1-\theta}
$$

subject to his budget constraint. By that time the ability shock is revealed, so that $h_{t}$ is known, and the agents do not face any uncertainty anymore. We further assume the unemployment benefits to be financed by a proportional tax levied on the net revenues of both the employed and unemployed individuals. By net revenues we mean after deduction of the educational cost $\left(1+r_{t}\right) e_{t}$. Taxes are thus non distortional and any effect on educational spending will be exclusively due to the presence of the unemployment benefit.

The individually relevant budget constraint depends on the realization of the ability shock $z_{t}$. For those who prefer to work, the budget constraint is 
given by

$$
c_{t}+s_{t}=\left(h_{t} w_{t}-\left(1+r_{t}\right) e_{t}\right)\left(1-\tau_{t}\right) ;
$$

while those who decide to enjoy the unemployment benefits system, are faced with

$$
c_{t}+s_{t}=\left(\Omega_{t}-\left(1+r_{t}\right) e_{t}\right)\left(1-\tau_{t}\right),
$$

where $\tau_{t}$ is the tax rate.

The first order condition for the savings decision is given by

$$
s_{t}= \begin{cases}\left(1-\tau_{t}\right)\left(\Omega_{t}-\left(1+r_{t}\right) e_{t}\right) p_{t+1} \equiv s_{t(\Omega)} & \text { for } h_{t} w_{t} \leq \Omega_{t} \\ \left(1-\tau_{t}\right)\left(h_{t} w_{t}-\left(1+r_{t}\right) e_{t}\right) p_{t+1} \equiv s_{t\left(z_{t}\right)} & \text { otherwise }\end{cases}
$$

with

$$
p_{t+1}=\left(1+(1+\rho)^{\frac{1}{\theta}}\left(1+r_{t+1}\right)^{\frac{\theta-1}{\theta}}\right)^{-1}
$$

the propensity to save.

In his first life-period, the agent chooses his educational effort in real terms $e_{t}$ in order to maximize his expected indirect utility subject to his individual human capital accumulation rule (1). He faces uncertainty as he does not know ex ante what will be the returns to his investment in education $-z_{t}$ is unknown ex ante-. When maximizing his indirect utility with respect to his educational effort, the agent takes into account the fact that his choice of $e_{t}$ will affect his probability of earning a wage smaller than the unemployment benefit. In particular this probability is given by

$$
\begin{aligned}
& =0 \text { if } \frac{\Omega_{t}}{H_{t-1}^{1-\beta} e_{t}^{\beta} w_{t}} \leq a \\
\frac{\Omega_{t} /\left(H_{t-1}^{1-\beta} e_{t}^{\beta} w_{t}\right)-a}{b-a} & \in(0,1) \text { if } \frac{\Omega_{t}}{H_{t-1}^{1-\beta} e_{t}^{\beta} w_{t}} \in(a, b) \\
& =1 \text { if } \frac{\Omega_{t}}{H_{t-1}^{1-\beta} e_{t}^{\beta} w_{t}} \geq b .
\end{aligned}
$$

This probability is indeed clearly determined by the value of the threshold $\Omega_{t} / H_{t-1}^{1-\beta} e_{t}^{\beta} w_{t} \equiv \Pi\left(e_{t}\right)$, which depends on the individual level of educational investment $e_{t}$. If we want unemployment benefits to have some effect on the individual's education decision, without however annihilating the incentive to carry out educational investment, $\Omega_{t}$ should be fixed such that, given the level of educational spending $e_{t}^{*}$ the individual has chosen, we have that 


$$
a<\Pi\left(e_{t}^{*}\right)<b
$$

Indeed, if $\Omega_{t} \leq a H^{1-\beta} a_{t} e_{t}^{* \beta} w_{t}$, unemployment benefits are too low to have any effect on the individual's decision concerning his effort. The problem reduces to the one without any unemployment benefit treated in Rillaers and Durán (1998). When on the other hand $\Omega_{t} \geq b H_{t}^{1-\beta} e_{t}^{* \beta} w_{t}, \Omega_{t}$ is so high that the individual has no incentive anymore to invest in education. In that case the only optimal effort is the corner solution $e_{t}^{*}=0$.

Another condition on $\Omega_{t}$ which needs to be fulfilled in order to avoid corner solutions, is

$$
\begin{aligned}
& \frac{1}{1-\theta} \int_{a}^{\Pi\left(e_{t}^{*}\right)}\left(\Omega_{t}-\left(1+r_{t}\right) e_{t}^{*}\right)^{1-\theta} f\left(z_{t}\right) d z_{t} \\
& +\frac{1}{1-\theta} \int_{\Pi\left(e_{t}^{*}\right)}^{b}\left(z_{t} H_{t-1}^{1-\beta} e_{t}^{* \beta} w_{t}-\left(1+r_{t}\right) e_{t}^{*}\right)^{1-\theta} f\left(z_{t}\right) d z_{t}>\frac{\Omega_{t}^{1-\theta}}{1-\theta}
\end{aligned}
$$

(5) states that the expected indirect utility derived from making an apparently optimal effort should be superior to the utility derived from ex ante choosing the unemployment benefit without making any educational investment, and hence without contracting debts. If it is not, it is clear that the optimal decision will again be the one of zero investment.

Optimal educational investment will be the solution of the expected indirect utility maximization problem, which is equivalent to

$$
\begin{aligned}
\max _{e_{t}} & \int_{a}^{\Pi\left(e_{t}\right)}\left(\Omega_{t}-\left(1+r_{t}\right) e_{t}\right)^{1-\theta} f\left(z_{t}\right) d z_{t} \\
& +\int_{\Pi\left(e_{t}\right)}^{b}\left(z_{t} H_{t-1}^{1-\beta} e_{t}^{\beta} w_{t}-\left(1+r_{t}\right) e_{t}\right)^{1-\theta} f\left(z_{t}\right) d z_{t}
\end{aligned}
$$

subject to

$$
\max \left\{a H_{t-1}^{1-\beta} e_{t}^{\beta} w_{t}, \Omega_{t}\right\}-\left(1+r_{t}\right) e_{t} \geq 0
$$

The constraint (6) ensures that the individual will be able to repay his debt even in the worst of the states tomorrow. In the absence of unemployment benefits, when $\Omega_{t}=0$, this constraint would reduce to $a H_{t-1}^{1-\beta} e^{\beta} w_{t}-(1+$ $\left.r_{t}\right) e_{t} \geq 0$, or equivalently

$$
e_{t} \leq H_{t-1}\left(\frac{a w_{t}}{1+r_{t}}\right)^{\frac{1}{1-\beta}}
$$


This expression will be referred to as the borrowing limit of the agent. The introduction of an unemployment benefit $\Omega$ satisfying (4) may relax this borrowing limit, allowing for higher levels of indebtedness; this occurs when

$$
\frac{\Omega}{1+r_{t}}>H_{t-1}\left(\frac{a w_{t}}{1+r_{t}}\right)^{\frac{1}{1-\beta}}
$$

in which case the relevant, relaxed, borrowing limit is given by

$$
e_{t} \leq \frac{\Omega_{t}}{\left(1+r_{t}\right)}
$$

Proposition 1 For any level of the unemployment benefit $\Omega_{t}$ satisfying (4) and (5), given a wage $w_{t}>0$ and an interest rate $r_{t}>-1$, we have that

a) when the unemployment benefit relaxes the borrowing limit, the optimal choice of educational investment $e_{t}$ is unique and interior for any value $\theta \in$ $(0, \infty]$, in the sense that (9) holds with strict inequality.

b) when the unemployment benefit does not relax the borrowing limit, and for $\theta \geq 1$, the optimal choice of educational investment $e_{t}$ is unique and interior in the sense that (7) holds with strict inequality.

See appendix A for a proof.

For $\theta \in(0,1)$ nothing can be said in general; depending on the values of the parameters the solution may be either interior, or a corner solution in which case it is given by $e_{t}^{*}=H_{t-1}\left(a w_{t} /\left(1+r_{t}\right)\right)^{\frac{1}{1-\beta}}$. Interior solutions are characterized by the following first order condition:

$$
\begin{array}{r}
\beta\left(\frac{e_{t}}{H_{t-1}}\right)^{\beta-1} w_{t} \int_{\Pi\left(e_{t}\right)}^{b} z_{t}\left(z_{t} H_{t-1}^{1-\beta} e_{t}^{\beta} w_{t}-\left(1+r_{t}\right) e_{t}\right)^{-\theta} f\left(z_{t}\right) d z_{t} \\
=\left(1+r_{t}\right)\left[\frac{\Pi\left(e_{t}\right)-a}{b-a}\left(\Omega_{t}-\left(1+r_{t}\right) e_{t}\right)^{-\theta}\right. \\
\left.+\int_{\Pi\left(e_{t}\right)}^{b}\left(z_{t} H_{t-1}^{1-\beta} e_{t}^{\beta} w_{t}-\left(1+r_{t}\right) e_{t}\right)^{-\theta} f\left(z_{t}\right) d z_{t}\right]
\end{array}
$$

We have that the individual will invest in his education up to the point where the expected return of the last unit of educational investment is equal to its marginal cost. From (10) we can however not unambiguously deduce what will be the effect of an unemployment benefit on individual educational investment. We will therefore, in the next subsection, develop some numerical exercises. 


\subsection{The effect of unemployment benefits on individual investment}

In order to examine the effect of unemployment benefits on individual educational investment, we carry out some numerical exercises in a partial equilibrium framework, in the sense that we examine the impact of unemployment benefits on investment at given prices. We adopt the following settings for the parameters: we assume zero population growth: $n=0$; the share of capital in total income $\alpha$ is fixed to 0.3 ; the relative weight of individual effort in the human capital accumulation rule $\beta$ is set to 0.1 ; the psychological discount rate $\rho$, is fixed to 1.5. We further set $\mu=3$, which gives us accumulated growth rates between 1.7 and 2; this implies annual growth rates between $1.7 \%$ and $2.3 \%$, given the fact that each generation is assumed to live for 30 years. Capital per efficiency unit $K_{t} / L_{t}$ is set to 0.032 in order to obtain an average of $4 \%$ for the annual interest rate. We set $\theta$, the degree of risk aversion, equal to 3 , as this gives us the richest results ${ }^{3}$. We consider three levels of uncertainty, $\sigma=1 / \sqrt{3}, \sigma=1.3$ and $\sigma=1.4$, and we let $\Omega_{t}$ vary between 0 and its value for which optimal investment reduces to zero because of the no-verification of condition (5).

Two opposite effects of unemployment benefits on educational investment can be distinguished. On the one hand, by guaranteeing a minimum income independent of individual educational spending and of the resulting productivity, an unemployment benefit is likely to have a discouraging effect. Agents have an incentive to spend less on education, since by doing so they will be less indebted, and hence they will have to pay back less in the next period. On the other hand, $\Omega_{t}$ may relax the borrowing limit (7), allowing for higher levels of educational investment. Indeed, when the borrowing limit prevents the upper bound of potential returns to education $b$ to have the same weight as the lower bound $a$ in the decision on investment, due to the fact that effort is downward restricted by this limit, relaxing it will adjust the relative weights of both bounds in favor of the upper one; stated differently, when the introduction of an unemployment benefit relaxes the borrowing limit, the range of admissible levels of investment will be extended upwardly. This allows the high productivity, potentially resulting from educational investment, to gain weight in the decision, compensating to a greater extent for the possibility of low productivity, and so inducing the individual to invest

\footnotetext{
${ }^{3}$ We did similar exercises for lower values of $\theta$ : for $\theta<1$ we obtained a monotonous decrease in educational investment when an unemployment benefit is introduced. For $\theta=1$ we observed the same rich behaviour of educational spending in presence of an unemployment benefit as for values of $\theta>1$ as treated here.
} 
more.

Figure 1: Individual investment effort

$$
\text { a. } \sigma=1 / \sqrt{3}
$$

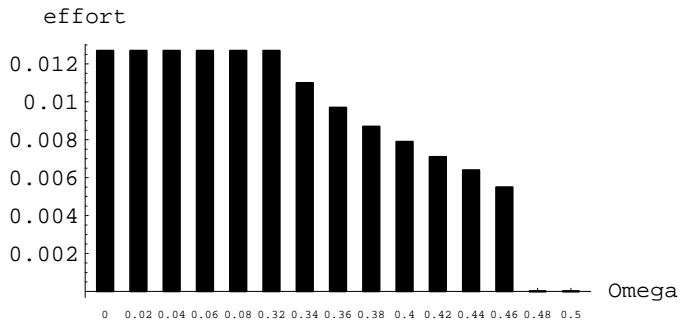

b. $\sigma=1.3$

c. $\sigma=1.4$

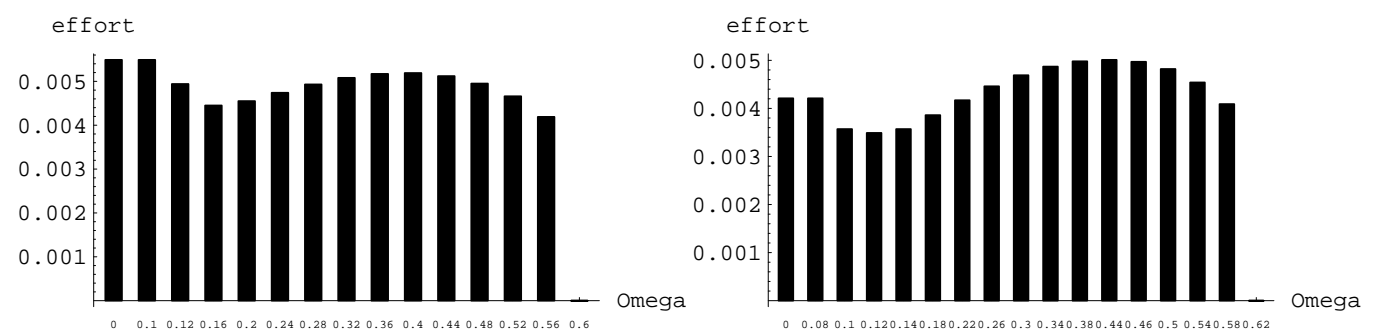

However, whereas the discouraging effect is always observed, the introduction of an unemployment benefit does not always relax the borrowing limit. Indeed, the borrowing limit relaxing effect will only take place if (8) holds. At given prices, the condition is likely to be fulfilled for sufficiently high levels of the benefit and/or when $a$ is small, or which is equivalent, for relatively high values of $\sigma$, the degree of uncertainty ( since $a=m-\sqrt{3} \sigma$ ). Stated differently, the borrowing limit relaxing effect of $\Omega_{t}$ is likely to exist when the borrowing limit is severe (this is when the difference $b-a$ is huge), implying an important asymmetry between the relative weight of the two bounds in the decision. These different effects are clearly observed in figure 1. When uncertainty is small, as is the case in graph a, the introduction of a sufficiently attractive unemployment benefit, -this is when the left inequality of condition (4) is verified-, does not relax the borrowing constraint; indeed, in this case condition (8) cannot be met, since the level of $\Omega_{t}$ required would violate condition (5), implying zero optimal effort. So there is only 
the discouraging effect playing a role, inducing lower levels of investment as $\Omega_{t}$ increases.

Graphs b and c show the case of higher degrees of uncertainty; although the introduction of a sufficiently high unemployment benefit here too initially induces a smaller investment, this negative effect converts into a positive one as $\Omega_{t}$ further increases, allowing condition (8) to be met. The borrowing limit relaxing effect takes thus place, and becomes dominating for certain values of $\Omega_{t}$, resulting in an increasing investment, which, according to graph c may even become superior to the one carried out in absence of any unemployment benefit. However, from a certain level of $\Omega_{t}$ on, the discouraging effect becomes the dominating one again, inducing lower levels of investment, which finally fall to zero when condition (5) is no longer met.

Hence we can conclude that whether the introduction of unemployment benefits has a positive or negative effect on educational investment, depends on whether these benefits relax the borrowing limit and to what extent. This relaxing effect only exists when uncertainty is high. Often the discouraging effect is however either the only effect, or at least the dominating one, inciting the individual to reduce his investment. In the following subsections we will take a closer look to the competitive equilibrium and the dynamics of the model, and we will examine the effect of unemployment benefits in the general equilibrium.

\subsection{General equilibrium}

It is convenient to redefine the unemployment benefits $\Omega_{t}$ provided by the government as a fraction of what would be the average labor income in this economy but without unemployment. So, we define the replacement ratio $\phi$ as

$$
\phi \equiv \frac{\Omega_{t}}{\mu H_{t-1}^{1-\beta} e_{t}^{\beta} w_{t}}
$$

Hence,

$$
\Omega_{t}=\phi \mu H_{t-1}^{1-\beta} e_{t}^{\beta} w_{t}
$$

where $\phi \mu \in(a, b)$, and $e_{t}$ is the sample average observed by the government in period $t$. From (11) it can easily be deduced that individuals with a productivity $z_{t}$ below $\phi \mu$ will choose not to work, but to join the social security system.

Given (11) and for $z_{t} \in[a, b]$, average savings are given by

$$
S_{t}=\frac{\phi \mu-a}{b-a} s_{t(\phi \mu)}+\int_{\phi \mu}^{b} s_{t\left(z_{t}\right)} f\left(z_{t}\right) d z_{t}
$$


where $(\phi \mu-a) /(b-a)$ is the fraction of the population which will prefer to join the social protection system. This fraction hence constitutes the unemployment rate in the economy, which we denote as $\Upsilon_{t}$.

Unemployment benefits are assumed to be financed by a proportional tax on all income; in order to have the budget balanced the tax revenues should equalize the total amount of unemployment benefits. So we have that

$$
\tau_{t}\left[\Upsilon_{t}\left(\Omega_{t}-\left(1+r_{t}\right) e_{t}\right)+\int_{\phi \mu}^{b}\left(z_{t} H_{t-1}^{1-\beta} e_{t}^{\beta} w_{t}-\left(1+r_{t}\right) e_{t}\right) f\left(z_{t}\right) d z_{t}\right]=\Upsilon_{t} \Omega_{t}
$$

The supply side of the economy is represented by an aggregate neoclassical production function: a single representative firm endowed with a CobbDouglas technology, behaving competitively and hiring labor and capital. As there is no aggregate uncertainty the firm's problem is essentially deterministic. The firm will choose in every period some capital stock and some effective labor so as to verify the usual first order conditions which equalizes the marginal productivity of each production factor to its price.

Equilibrium in the labor market will be more subtle as not the total population will be employed. At period $t$ only a proportion $\left(1-\Upsilon_{t}\right)$ of the total population $N_{t-1}$ works, the remaining $\Upsilon_{t} N_{t-1}$ individuals are unemployed. As this working part of the population consists of the individuals who have a level of human capital $h_{t\left(\phi \mu<z_{t}<b\right)}^{w}>h_{t\left(a \leq z_{t} \leq \phi \mu\right)}$, their average human capital level will be higher than the average level over the total population. Indeed, we have that

$$
H_{t}^{w}=\int_{\phi \mu}^{b} z_{t} H_{t-1}^{1-\beta} e_{t}^{\beta} f^{w}\left(z_{t}\right) d z_{t}
$$

where $f^{w}\left(z_{t}\right)=(b-\phi \mu)^{-1}$ is the density function of $z_{t} \in[\phi \mu, b]$. Solving the integral and using (2) we obtain

$$
H_{t}^{w}=\frac{\phi \mu+b}{2} \frac{H_{t}}{\mu}>H_{t}
$$

We can thus conclude that the presence of unemployment benefits increases average labor productivity.

The equilibrium in the labor market requires the demand for labor $L_{t}$ to be equal to the supply $\left(1-\Upsilon_{t}\right) N_{t-1} H_{t}^{w}$, which substituting for $\Upsilon_{t}$ and $H_{t}^{w}$ gives $L_{t}=\Phi N_{t-1} H_{t}$ with $\Phi \equiv\left(b^{2}-(\phi \mu)^{2}\right) /(2 \mu(b-a))$. It is straightforward to show that the optimality conditions of the firm including already this market clearing condition are

$$
\begin{aligned}
w_{t} & =(1-\alpha) \Phi^{-\alpha} k_{t}^{\alpha} \\
1+r_{t} & =\alpha \Phi^{1-\alpha} k_{t}^{\alpha-1}
\end{aligned}
$$


where $k_{t} \equiv K_{t} /\left(N_{t-1} H_{t}\right)$, the quantity of capital per capita in efficiency units.

The demand for credit consists of the firm's gross investment $K_{t+1}$ and of the current young generation's investment in human capital $N_{t} e_{t+1}$. The clearing of the capital market implies that aggregate savings, -the supply of credit-, should equal investment in physical and human capital. Thus

$$
N_{t-1} S_{t}=K_{t+1}+N_{t} e_{t+1}
$$

The goods markets will clear as soon as the credit and labor markets do so and the individual budget constraint holds.

Definition 1 Given an initial capital stock $K_{0}$, an initial stock of human capital $H_{-1}$, and an initial population $N_{t-2}$, an intertemporal equilibrium with perfect foresight is a sequence $\left\{e_{t}, K_{t}, L_{t}, h_{t}, H_{t}, s_{t}, S_{t}, \Omega_{t}, \tau_{t}\right\}$ and a sequence of prices $\left\{\left(1+r_{t}\right), w_{t}\right\}$, which for all $t \geq 0$ satisfy (1), (2), (3), (4), (5), (6), (10), (12), (13), (15), (16), and the three market equilibrium conditions: (17), $L_{t}=\Phi N_{t-1} H_{t}$ and the clearing of the goods market.

\subsection{Dynamics}

The law of motion of average human capital gives us the growth $g_{t}$ of human capital

$$
\frac{H_{t}}{H_{t-1}}=1+g_{t}=\mu H_{t-1}^{-\beta} e_{t}^{\beta} .
$$

A balanced growth path is defined as a sequence of competitive equilibria along which average human capital grows at a constant rate $g>0$. The other average variables will also grow at this rate $g$, while the aggregate ones grow at a rate $n+g$. In order to have variables which remain stationary along the balanced growth path, we will carry out the following transformation. Let $\hat{e}_{t}=e_{t} / H_{t-1}$, while savings per efficiency unit are defined as $\hat{s}_{t}=s_{t} / H_{t}$ so that $\hat{S}_{t}=\frac{\phi \mu-a}{b-a} \hat{s}_{t(\phi \mu)}+\int_{\phi \mu}^{b} \hat{s}_{t\left(z_{t}\right)} f\left(z_{t}\right) d z_{t}$. Capital stock per efficiency unit does already remain constant along a balanced growth path.

Due to the complicated nature of the system we do not provide a proof for the existence, uniqueness, and global stability of the steady state. Numerical exercises seem to indicate however, that at least for some reasonable values of the parameters, the steady state exists, is unique and at least locally stable. In the next section we rely on numerical methods in order to study the effect of unemployment benefits on the steady state educational investment $\hat{e}$. 


\subsection{The effect of unemployment benefits on steady state educational investment}

In this numerical example we adopt the same settings for the parameters as before: $n=0 ; \alpha=0.3 ; \rho=1.5 ; \mu=3, \beta=0.1$ and $\theta=3$, which gives us values for the annual interest rate fluctuating around $5 \%$. We consider the three cases studied previously in the partial equilibrium: $\sigma=1 / \sqrt{3}, \sigma=1.3$ and $\sigma=1.4$. We let the replacement ratio $\phi$ vary from 0 up to a value which in the general equilibrium appears to violate condition (5), leading to an optimal effort equal to 0 . For the three cases considered this upper value for $\phi$ is respectively $1.2,1.5$, and 1.6. We examine the effect of the replacement ratio on investment in the steady state. We also compute the corresponding unemployment and tax rates.

¿From figure (2) we observe the same patterns as in the partial equilibrium analysis: the general trend consists in a decrease of educational spending whenever unemployment benefits are introduced such as to be sufficiently attractive to induce unemployment. This is due to the fact that the agent receives these unemployment benefits independently of whether he invests or not in education, which induces him to decrease his educational effort, as effort is costly anyway. Here again, while for small values of $\sigma$ this effect is monotonously negative, for higher values of $\sigma$, effort may be increasing for certain values of $\phi$. This is because of the borrowing limit relaxing effect, which unemployment benefits are likely to have when uncertainty is high, and which may overcompensate the discouraging effect. When $\phi$ reaches a certain value, the discouraging effect becomes the dominating one, depressing optimal effort again, until the latter falls to zero.

Hence, only for high degrees of uncertainty $\Omega$ may have a positive effect, even leading to an optimal level of investment superior to the one which would be optimal if there were no unemployment benefits. In part c of figure (2) we observe that this is the case for $\phi=0.7$. Notwithstanding the higher growth rate this larger effort implies on the aggregate level, one may not loose sight of the corresponding unemployment and tax rate, which in this case are quite high: $31 \%$ and $21 \%$ respectively; nor of the subsequent welfare loss for at least part of the population, due to the taxes and the drop in production resulting from the reduced size of the active labor force.

In the next section we will have a look at the implications of unemployment benefits in terms of wage inequality, unemployment and welfare. 
Figure 2: Steady state educational investment effort and corresponding unemployment and tax rates

$$
\text { a. } \sigma=1 / \sqrt{3}
$$
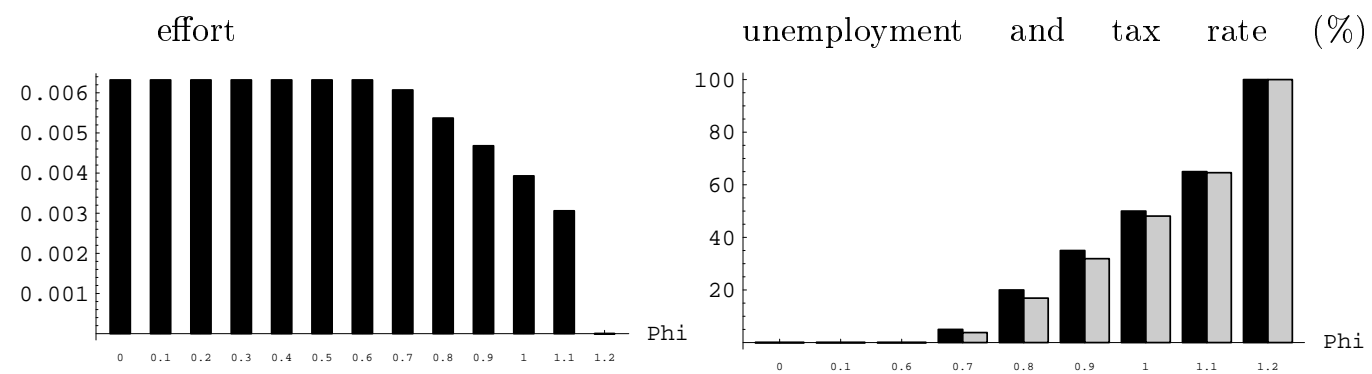

b. $\sigma=1.3$
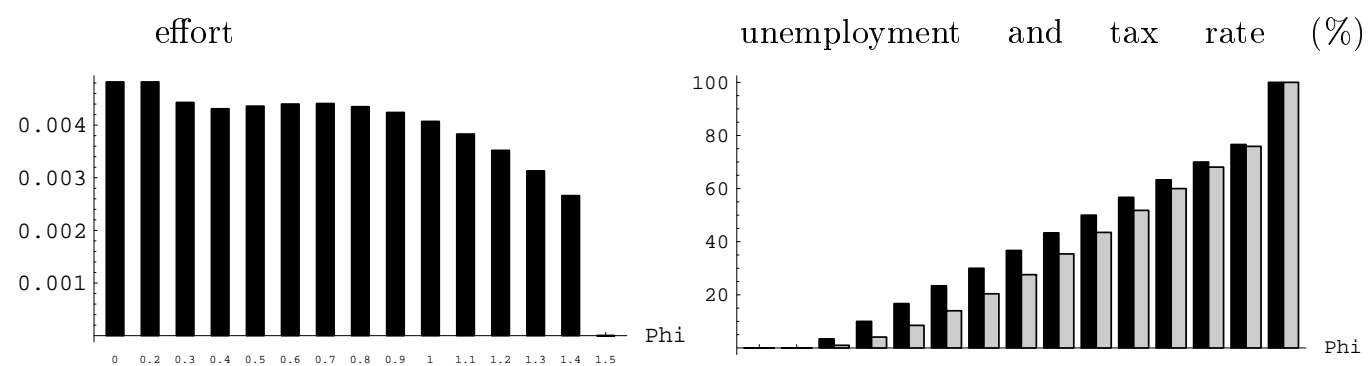

c. $\sigma=1.4$

effort

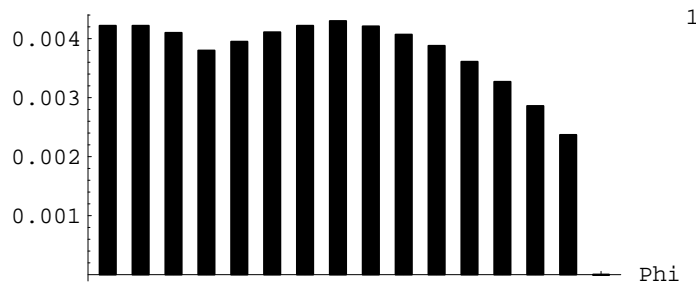

unemployment and tax rate (\%)

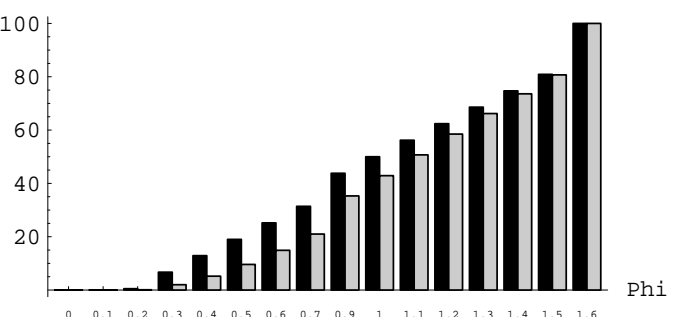




\section{A comparison between the United States and Europe}

In this section we develop a numerical example of our model in order to approximate the economies of Western Europe and of the United States in terms of economic performance. In particular, we reproduce some stylized facts that characterize these two economies and underline their contrasting performance in terms of some macroeconomic indicators. The parameters in the two constructed hypothetical economies only differ in respectively the presence and the absence of unemployment benefits. We assume that both economies are hit by a common skill-biased technological shock which increases the productivity of the highly skilled workers. We rely on previous work by Marimóm and Zilibotti (1997) according to which such a skilledbiased technological change can generate quite different responses in both economies, due to one institutional difference, namely the degree of social protection.

\subsection{Europe vs. United States: some stylized facts}

Europe and the United States are characterized by a contrasting performance of their economies, but both countries also display similarities. A first manifest difference between the two economies concerns unemployment. Indeed, unemployment has increased dramatically in Western Europe, from an average rate of $4 \%$ during the period $1971-1980$ to an average of $9 \%$ during the period 1981-1990. Today it approaches 11\% (see European Commission 1997, page 197). In the United States however, unemployment has been maintained during the last thirty years at a rough average rate of $6 \%$.

Growth rates, on the contrary, have been quite similar in both economies during the last 25 years, though slightly higher in the United States (about $2.5 \%$ a year) compared to Europe (about $2.3 \%$ a year). Different employment rates and similar growth rates necessarily imply differences in productivity growth. If we compare the annual percentage change in the gross domestic product per employed, we indeed observe differences between the two economies, in favour of the European one. The average gap between the percentage change of labor productivity in the European Union and the United States has been above 1\% per year for the period 1973-1992: the average annual growth rate of labor productivity in Europe has been 2.2\%, compared to $1.1 \%$ in the United states (Maddison 1995, p.81).

Although Europe has also achieved considerable progress as far as ed- 
ucation is concerned, the American labor force is still characterized by a higher instruction level: the percentages of adult population having achieved secondary school, non university superior education and university are respectively $41 \%, 15 \%$ and $15 \%$, compared to averages of $35 \%, 7 \%$ and $8 \%$ for Europe (OCDE 1993, p.86).

This advantage in education level is however accompanied by an increasing wage inequality, which is partially the result of the augmenting gap between the earnings of the qualified and the non-qualified; whereas university graduates enjoyed a sustained growth of their real income during the last decade, the low skilled faced a decrease in their real earnings. As a result the gap between the earnings of the high and low skilled has increased from $15 \%$ to 50\% (OCDE 1993). In Europe, social inequalities are more limited, despite the higher unemployment rate (Marimóm and Zilibotti 1997).

In the next subsection we aim to reproduce the above stylized facts by developing a numerical example of our model, and by introducing a skillbiased technological shock.

\subsection{A numerical example of the model and the skill- biased technological shock}

We construct two different hypothetical economies E1 and E2 by developing a numerical example of the model. The only difference between both economies concerns the extent of social insurance. More particularly, one economy, denoted as E1, will be characterized by the absence of unemployment benefits, implying a replacement ratio $\phi=0$. Whereas the other economy, denoted by $\mathrm{E} 2$, is assumed to provide unemployment benefits, and is hence characterized by a strictly positive replacement ratio $\phi$. E1 can be considered as an approach to a US-type laissez-faire economy, while E2 rather stands for the European welfare society. The unemployment benefits are assumed to be financed by proportional, non distortional taxes levied on the income of both employed and unemployed individuals. The two economies are identical as far as all other parameters are concerned.

We keep the same settings as before for $\alpha$ and $\rho$. We choose $\beta$ and $\mu$ such as to obtain a steady state value for the interest rate over the whole period of 5.18 , and an annual growth rate of $2 \%$; this gives $\beta=0.1$ and $\mu=3$. For simplicity's sake we still assume a uniform earnings distribution, although we are aware of the fact that this does not correspond to reality ${ }^{4} \sigma$ is set to $1 / \sqrt{3}$,

\footnotetext{
${ }^{4}$ According to Díaz-Giménez, Quadrini and Ríos-Rull (1997) the density functions of the earnings, income and wealth distributions are skewed; they present a fat lower tail and
} 
which gives an earnings dispersion characterized by a ratio highest wage to lowest wage equal to 2 . Although this might seem underestimated at first sight, it can be considered as a reasonable characterization for the earnings dispersion taking into account that we assume a uniform distribution ${ }^{5}$. The replacement ratio $\phi$ is set to 0.66 , implying that the unemployment benefits $\Omega_{t}$ amount to $66 \%$ of what would be the average labor income in this economy but without unemployment. Since for $\phi=0.66, \phi \mu<a$, this amount $\Omega_{t}$ will initially not be sufficiently high in order to induce unemployment.

Like in Marimóm and Zilibotti (1997) we assume that both economies are initially at their steady states, which we interpret as the situation of the early 70's. As the unemployment benefits in E2 are not sufficiently attractive, and hence do not induce any unemployment, the steady state is initially identical for both economies; it is characterized by the second column of table 1 .

We now introduce a skill-biased technological shock which hits both economies to the same extent, and which the individuals perfectly anticipate. This shock is assumed to summarize a process of rapid technological change, biased in favor of the skilled workers. Such a shock would have taken place in the 1980's, inducing a sharp rise in skill differentials (See Berman, Pound and Griliches 1994). According to Krueger (1993), the proliferation of computers at work has been the main responsible for this process, causing substantial changes in the relative productivity of various types of workers; in particularly it increased the productivity of the already highly productive workers. In our model we assume this phenomenon to be translated into an increase of the productivity of the relatively more highly productive workers, while leaving unchanged the productivity of the less productive ones. This is achieved by increasing the upper bound $b=\mu+\sqrt{3} \sigma$ of the support of the distribution of the productivity shock $z_{t}$, maintaining the lower bound $a=\mu-\sqrt{3} \sigma$ unchanged. This implies that the mean $\mu$ and the standard deviation $\sigma$ will increase. In particular we assume here that $\mu$ increases from its initial value 3 up to 3.6 , and $\sigma$ up to $\frac{1.6}{\sqrt{3}}$, verifying that $a$ remains equal

a thin upper tail.

${ }^{5}$ With the above characterization we obtain the following values for the ratios between deciles of the earnings distribution: $D 9 / D 5=1.27, D 1 / D 5=0.67$ and $D 9 / D 1=1.7$. When comparing with real data this seems underestimated: in 1975 we observe for the US: $D 9 / D 5=1.93, D 1 / D 5=0.41$ and $D 9 / D 1=4.71$; for Germany: $D 9 / D 5=1.50$, $D 1 / D 5=0.75$ and $D 9 / D 1=2.00$; and for the UK: $D 9 / D 5=1.66, D 1 / D 5=0.70$ and $D 9 / D 1=2.37$ (See Nickell and Bell, 1996, p. 310). It should be taken into account however, that a uniform distribution as assumed in this paper, does not account for the upper and lower tails of the density function characterizing the earnings distribution. These tails reflect the existence of extreme upper and lower observations, which are determinant for the deciles D1 and D9 notwithstanding their small density. 
to 2 .

\subsection{Results}

Table 1 summarizes the results. Thirty years after the shock, at $t=1$, we observe that, whereas in E1 unemployment is still inexistent, E2 now faces an unemployment rate of 11.75. As a consequence of the shock average productivity $\mu$, and hence $\phi \mu$ has increased, and has become superior to $a$. For the individuals with a productivity up to $z=\phi \mu$, it is now more attractive to get unemployed and receive the unemployment benefit $\Omega$, than to keep on working. The financing of these unemployment benefits requires the levying of a tax rate of $8.22 \%$ on net income.

The technological shock increases the average productivity per effectively employed unit of efficiency labor in both economies, but this increase will be more accentuated in E2 compared to E1. This is obviously due to the fact that in E2 the active labor force does not include the less productive part of the population.

The growth rate increases as a consequence of the technological shock, and the extent to which it does is approximately the same in both economies. The increase of average productivity due to the shock, accounts for this increase of the growth rate, and this notwithstanding the diminishing educational effort per efficiency unit. However, if we take a look at what happens in the long run, this is at the new steady state, we observe that the growth rate in both economies slightly decreases again. This is due to the persistent decrease in educational effort per efficiency unit, which also accounts for the decrease in the average productivity in the long run.

Investment per efficiency unit $\hat{e}$ in both economies indeed decreases in $t=1$, and continues to do so up to when the new steady state is reached. On the one hand this is a direct consequence of the substitution effect induced by a higher expected average productivity of education $\mu^{6}$. On the other one, the higher quantity of available units of efficiency labor leads to a lower real wage per efficiency unit and a higher interest rate implying decreasing returns to and increasing costs of educational investment. The more important decrease in the level of investment observed in the economy with unemployment benefits compared to the one without, is due to the presence of such benefits. As they do not relax the borrowing limit $\left(\hat{\Omega} /(1+r)<(a w /(1+r))^{\frac{1}{1-\beta}}\right)$, they have an exclusively discouraging effect on educational investment through

\footnotetext{
${ }^{6}$ We did some numerical exercises in order to analyze the effect of an increase of $\mu$ on educational investment, and observed that this effect is always negative.
} 
the guaranteeing of an unconditional minimum income ${ }^{7}$.

Table 1: Comparisons 1 period after the shock and at steady states

\begin{tabular}{|c|c|c|c|c|c|}
\hline & $\begin{array}{c}t=0 \\
\text { E1 E2 }\end{array}$ & $\begin{array}{c}t=1 \\
\mathrm{E} 1\end{array}$ & $\mathrm{E} 2$ & $\begin{array}{c}t \rightarrow \infty \\
\text { E1 }\end{array}$ & $\mathrm{E} 2$ \\
\hline Educational investment $\hat{e}$ & 0.00632 & 0.0053 & 0.00467 & 0.0045 & 0.00408 \\
\hline Propensity to save $\frac{N s}{Y}$ (in \%) & 12.6 & 11.7 & 11.7 & 11.0 & 11.2 \\
\hline Growth factor (whole period) & 1.8 & 2.14 & 2.09 & 2.10 & 2.08 \\
\hline Growth rate (annual) & $2 \%$ & $2.56 \%$ & $2.51 \%$ & $2.5 \%$ & $2.47 \%$ \\
\hline Unemployment rate & 0 & 0 & $11.75 \%$ & 0 & $11.75 \%$ \\
\hline Tax rate & 0 & 0 & $8.22 \%$ & 0 & $8.22 \%$ \\
\hline Interest factor $(1+\mathrm{r})($ Whole period $)$ & 5.18 & 6.02 & 5.6 & 6.75 & 6.13 \\
\hline Interest rate $(1+\mathrm{r})($ annual $)$ & $5.6 \%$ & $6.2 \%$ & $5.9 \%$ & $6.57 \%$ & $6.23 \%$ \\
\hline \multicolumn{6}{|l|}{ Increase in labor productivity } \\
\hline with respect to period $t=0$ & - & $11.3 \%$ & $13.2 \%$ & $3.8 \%$ & $7.5 \%$ \\
\hline$\frac{\text { lowest income }}{\text { highest income }} \times 100 \%$ & $50.0 \%$ & $38.5 \%$ & $46.0 \%$ & $38.5 \%$ & $46.0 \%$ \\
\hline$\frac{\text { income bottom quintile }}{\text { income top quintile }} \times 100 \%$ & $57.9 \%$ & $47.5 \%$ & $50.0 \%$ & $47.5 \%$ & $50.0 \%$ \\
\hline Atkinson index & 0.759 & 0.978 & 0.959 & 0.978 & 0.959 \\
\hline
\end{tabular}

As a consequence of the shock, income inequality has sharpened considerably in both economies, although to a larger extent in E1 compared to E2: the ratio between lowest and highest income has decreased, as did the ratio of the income share earned by the bottom quintile and the top quintile of the income distribution; the Atkinson index ${ }^{8}$ has increased, again indicating

\footnotetext{
${ }^{7}$ Although the model reproduces the stylized fact concerning education, -a higher instruction level in the U.S compared to the one in Europe- one must be aware of the fact that what causes this difference to arise in the model, -the absence and presence of an unemployment benefit- may indeed contribute to the phenomenon observed in reality, but does obviously not constitute the only explanatory variable

${ }^{8}$ The Atkinson index is a measure for inequality defined as $I=1-$
} 
higher inequality. Although the technological shock has an overall inequality increasing effect, in E2 this is partially offset by the existence of unemployment benefits. In E1 however, as no insurance exists, the wider productivity gap is entirely translated into an increasing income inequality.

Figure 3: Utility

$$
\mathrm{t}=1 \quad \mathrm{t}=4
$$

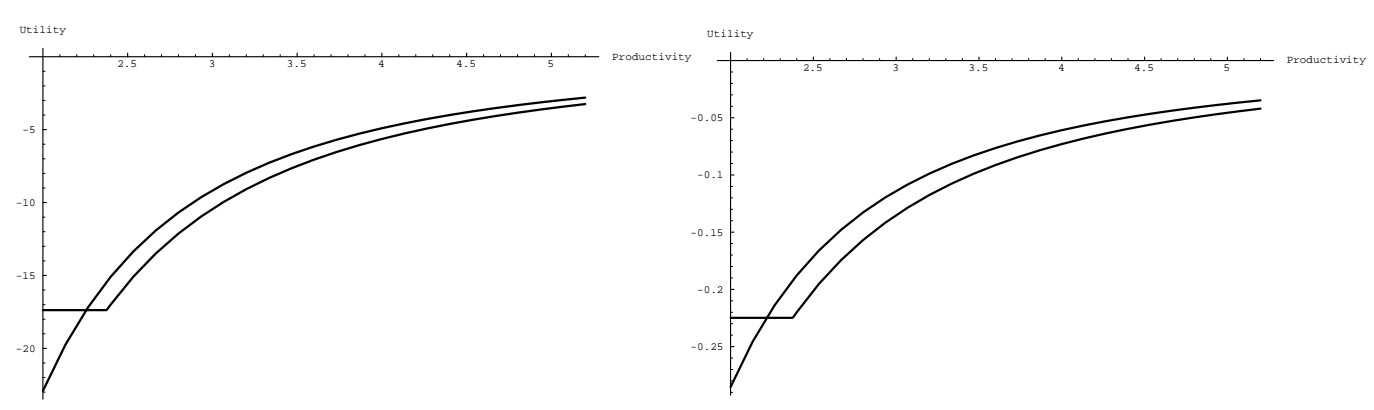

The less productive part of the population is clearly better off with than without unemployment benefits, while more highly productive workers would prefer a no insurance system, in order to avoid paying taxes. Figure (3) represents the utility corresponding to the different levels of productivity in both economies, for the first and the fourth period subsequent to the shock ${ }^{9}$. From these graphs we can indeed deduce that, while highly productive workers loose in utility terms because of the taxes they pay, the part of the population with the lowest productivity, benefits from utility gains from the provision of unemployment benefits. This part however, only represents a small share of total population which would imply a rather scarce political support for introducing unemployment benefits. Note also that the gap between the two curves becomes wider in relative terms through time, due to the higher growth rate in E1 compared to E2. A consequence will be that political support for unemployment benefits will diminish over time, as an ever decreasing part of the population would benefit from it in terms of utility. Indeed, while in the first period after the shock this part represents $8 \%$ of the population, it decreases to $6.8 \%$ in the fourth period.

$\exp \left[\sum_{i=1}^{n} f_{i} \log _{e}\left(Y_{i} / \bar{Y}\right)\right]$, where $Y_{i}$ denotes the income of those in the $i$ th income range; $f_{i}$ denotes the proportion of the population with incomes in the $i$ th range; and $\bar{Y}$ denotes the mean income. (Atkinson 1983)

${ }^{9} \mathrm{~A}$ welfare analysis at the steady state is impossible to be carried out as utility continuously grows at the steady state. Therefore we compare utility levels at certain points in time, and not at the steady state. 


\section{Concluding remarks}

In this paper we have examined whether unemployment benefits can induce the individual to invest more in his education when the returns to this investment are characterized by uncertainty. This analysis is carried out in an overlapping generations model in which human capital investment through educational effort accounts for endogenous growth. We find that the introduction of unemployment benefits generates two opposite effects on individual educational investment. On the one hand, unemployment benefits, by guaranteeing a minimum income independently of individual investment and productivity, induce lower levels of effort. On the other hand, these benefits may relax the borrowing limit, allowing for higher levels of borrowing. This second, investment encouraging effect only exists provided the introduction of unemployment benefits actually does relax the borrowing limit, which is only the case for rather high degrees of uncertainty.

Whether the introduction of an unemployment benefit finally induces higher levels of educational investment depends thus on whether these benefits relax the borrowing limit and to what extent. However, often the discouraging effect is either the only effect, or at least the dominating one, inciting the individual to reduce his investment. Even in the case in which unemployment benefits do relax the borrowing limit, the ultimate effect on investment is very sensitive to the amount of the benefit, which makes it an instrument quite awkward to handle.

According to these results, unemployment benefits are thus not necessarily growth enhancing. Accompanying them with subsidies to education may be a way to cancel this pervert, investment reducing effect, preserving its other, more desirable consequences, like the reduction of income inequality. Indeed, when developing a numerical example of the model for two hypothetical economies which only differ in the presence and absence of unemployment benefits, we find that in the economy with unemployment benefits, the wage inequality is smaller than in the one without. In particular we observe that the agents with a low productivity are better off in terms of utility in an economy with unemployment benefits. We verify that the introduction of unemployment benefits helps the model to reflect some differences European data display with respect to North American data; in particular, the unemployment benefits seem to provide a possible explanation for the differences between both economies in terms of unemployment rate, labor productivity, education level and wage inequality.

Due to the taxes however, a vast majority of agents is worse off in an economy with unemployment benefits; political support in favor of an insur- 
ance system will thus be rather scarce. An extension of the present paper, in analogy with Glomm and Ravikumar (1992) and Alesina and Rodrik (1995), may hence be the study of the conditions necessary to lead to majority voting in favor of the introduction of unemployment benefits, and hence of more income equality.

\section{Appendix}

\section{Proof of proposition 1}

Define the objective function as

$$
\begin{aligned}
J\left(e_{t}\right)= & \frac{1}{1-\theta} \int_{a}^{\Pi\left(e_{t}\right)}\left(\Omega_{t}-\left(1+r_{t}\right) e_{t}\right)^{1-\theta} f\left(z_{t}\right) d z_{t} \\
& +\frac{1}{1-\theta} \int_{\Pi\left(e_{t}\right)}^{b}\left(z_{t} H_{t-1}^{1-\beta} e_{t}^{\beta} w_{t}-\left(1+r_{t}\right) e_{t}\right)^{1-\theta} f\left(z_{t}\right) d z_{t}
\end{aligned}
$$

for all $e_{t} \in[0, \bar{e}]$ where $\bar{e}_{t}$ is the maximum investment allowed by the borrowing limit.

For all $e_{t} \in\left(0, \bar{e}_{t}\right)$ the derivative of $J\left(e_{t}\right)$ with respect to $e_{t}$ is well defined and equal to

$$
\begin{aligned}
J^{\prime}\left(e_{t}\right)= & -\left(1+r_{t}\right) \int_{a}^{\Pi\left(e_{t}\right)}\left(\Omega_{t}-\left(1+r_{t}\right) e_{t}\right)^{-\theta} f\left(z_{t}\right) d z_{t} \\
& +\int_{\Pi\left(e_{t}\right)}^{b}\left(z_{t} H_{t-1}^{1-\beta} e_{t}^{\beta}-\left(1+r_{t}\right) e_{t}\right)^{-\theta}\left(z_{t} H_{t-1}^{1-\beta} \beta e_{t}^{\beta-1}-\left(1+r_{t}\right)\right) f\left(z_{t}\right) d z_{t} .(20)
\end{aligned}
$$

We distinguish two cases. When the unemployment benefit relaxes the borrowing limit (statement $a$ ), the relevant borrowing limit is given by (9), and hence $\bar{e}_{t}=\frac{\Omega_{t}}{1+r_{t}}$. We shall prove that for any $\theta \in(0, \infty]$ and for $z_{t} \sim$ $U[a, b], J\left(e_{t}\right)>J(0)$ and $J^{\prime}\left(\bar{e}_{t}\right)<0$, in which case there must be some interior $e_{t}^{*}$ which verifies $J^{\prime}\left(e_{t}^{*}\right)=0$, and which is the optimal choice of educational investment.

- $J\left(e_{t}\right)>J(0)$

This inequality is nothing but condition (5) and is therefore always verified. 
- $J^{\prime}\left(\overline{e_{t}}\right)<0$

After integrating (20) for respectively $\theta \in(0, \infty] \backslash\{1\}$ and for $\theta=1$, and after rearranging terms, it is straightforward to see that $J^{\prime}\left(\bar{e}_{t}\right)=-\infty$. Q.E.D.

When the unemployment benefit does not relax the borrowing limit, (statement $b$ ), $\bar{e}_{t}=H_{t-1}\left(\frac{a w_{t}}{1+r_{t}}\right)^{\frac{1}{1-\beta}}$. Here again, an interior solution is said to exist if $J\left(e_{t}\right)>J(0)$ and $J^{\prime}\left(\bar{e}_{t}\right)<0$.

- $J\left(e_{t}\right)>J(0)$

This inequality holds by an identical argument to the one above.

- $J^{\prime}\left(\bar{e}_{t}\right)<0$

(8) does not hold, which is equivalent to say that $\Omega_{t} \leq a H_{t-1}^{1-\beta} e_{t}^{\beta} w_{t}$ for $e_{t}=\bar{e}_{t}$, implying that $\Pi\left(\bar{e}_{t}\right)$ tends to $a$. Hence we have that $J^{\prime}\left(\bar{e}_{t}\right)$ reduces to $\int_{a}^{b}\left(z_{t} H_{t-1}^{1-\beta} \bar{e}_{t}^{\beta}-\left(1+r_{t}\right) \bar{e}_{t}\right)^{-\theta}\left(z_{t} H_{t-1}^{1-\beta} \beta \bar{e}_{t}^{\beta-1}-\left(1+r_{t}\right)\right) f\left(z_{t}\right) d z_{t}$; after integrating this last expression for respectively $\theta=1$ and $\theta \in$ $(1, \infty]$, and after rearranging terms, it is straightforward to see that $J^{\prime}\left(\bar{e}_{t}\right)=-\infty$.

Q.E.D. 


\section{References}

Alesina, A. and D. Rodrik (1995), "Distributive Politics and Economic Growth". Technical Report, CEPR .

Atkinson, A. (1995), "The Welfare State and Economic Performance," National Tax Journal, 48:171-198.

Atkinson, A. (1984), The Economics of Inequality. Second edition, Clarendon Press, Oxford.

Altonji, J. and T. Dunn (1996), "The Effects of Family Characteristics on the Return to Education," Review of Economics and Statistics 78:692-704.

Becker, G.S. (1975), Human Capital: a Theoretical and Empirical Analysis with Special Reference to Education. Second Edition, Columbia University Press, New York.

Berman, E., J. Pound and Z. Griliches (1994), "Changes in the Demand for Skilled Labor within U.S. Manufacturing: Evidence from the Annual Survey of Manufactures," Quaterly Journal of Economics 109:367-398.

Card, D. and A. Krueger (1992), "Does School Quality matter? Returns to Education and the Characteristics of Public Schools in the United States," Journal of Political Economy 100:1-40.

Dellas, H. (1997), "Unemployment Insurance Benefits and Human Capital Accumulation", European-Economic-Review 41:517-24.

Díaz-Gimenéz, J. (1997), V. Quadrini and J.-V. Ríos-Rull, "Dimensions of Inequality: Facts on the U.S. Distributions of Earnings, Income and Wealth," Federal Reserve Bank of Minneapolis Quaterly Review 21:1126-1150.

Drèze, J.H. and E. Malinvaud (1994), "Growth and Unemployment: the Scope for a European Initiative," European Economy 1:77-106.

European Commission (1997), "European economy", Directorate-General for Economic and Financial Affairs 63.

Glomm, G. and B. Ravikumar (1992), "Public versus Private Investment 
in Human Capital: Endogenous Growth and Income Inequality," Journal of Political Economy 100:819-834.

Jonas Agell, T.L. and H. Ohlsson (1997), "Growth and the Public Sector: a Critical Review Essay," European Journal of Political Economy 13:33-52.

Kodde, D.A. (1986), "Uncertainty and the Demand for Education," Review of Economics and Statistics 68:460-467.

Krueger, A.B. (1993), "How Computers Have Changed the Wage Structure: Evidence from Microdata," Quaterly Journal of Economics 108:33-60.

Levhari, D. and Y. Weiss (1974), "The Effect of Risk on the Investment on Human Capital," American Economic Review, 64:950-963.

Lindbeck, A. et. al. (1993), "Options for Economic and Political Reform in Sweden," Economic Policy 17:219-264.

Lindbeck, A. et. al. (1994), Turning Sweden around, MIT Press, Cambridge. .

Maddison, A. (1995), L'Economie mondiale 1820-1992. OECD Analyse et statistiques, Paris.

Marimón, R. and F. Zilibotti (1997), "Unemployment vs. Mismatch of Talents: Reconsidering Unemployment Benefits", mimeo.

Michel, P. (1993), "Le modèle à générations imbriquées, un instrument d'analyse macroéconomique," Revue d'Economie Politique 103:191-220.

Nickell, S.J. and B. Bell (1996), "Would Cutting Payroll Taxes on the Unskilled Have a Significant Impact on the Unemployed". In: D.J. Snower and G. de la Dehesa, eds., Unemployment Policy, Cambridge University Press, Cambridge.

OECD 1993, Etudes economiques de l'OCDE 1992-1993, Etats-Unis, OCDE.

Persson, T. and G. Tabellini (1994), "Is Inequality Harmful for Growth?," American Economic Review 84:600-621.

Rillaers, A. and J. Durán (1999), "Idiosyncratic Productivity Shocks, Bor- 
rowing Limits and Investment in Human Capital", mimeo, IRES-UCL.

Snow, A. and R.S. Warren (1990), "Human Capital Investment and Labor Supply under Uncertainty," International Economic Review 31:195-205.

Williams, J.T. (1979), "Uncertainty and Accumulation of Human Capital over the Life Cycle," Journal of Business 52:521-548. 